\title{
Dispositivos de memória para informação jurídica: análise de procedimentos de indexação
}

\author{
Memory devices for juridical information: analysis of indexing procedures
}

Márcia Ivo Braz
Bibliotecária. Mestre em Ciência da Informação pela Universidade Federal de Pernambuco - UFPE.
E-mail: marcia_ibraz@hotmail.com

Fabio Assis Pinho

Doutor em Ciência da Informação pela UNESP, campus de Marília. Professor Adjunto do Departamento de Ciência da Informação da Universidade Federal de Pernambuco - UFPE.

E-mail: fabiopinho@ufpe.br

\section{Resumo}

A Ciência da Informação, interdisciplinar, estabeleceu ligações com diversas áreas, especialmente a memória, uma vez que o surgimento dos registros do conhecimento e a necessidade de organização e acesso à informação resultaram nos chamados lugares de memória, onde se constituíram práticas para conservação, acesso e disseminação dos registros. Assim, organização e representação do conhecimento guardam compromisso com a recuperação, o acesso e a apropriação da informação. Além disso, enquanto dispositivos de memória, permitem que a área ou a comunidade discursiva possam ser compreendidas e reconstituídas, o que aplicado às instituições que lidam com o Direito pode ter efeitos mais abrangentes no sentido do exercício da cidadania, promoção do acesso às informações aos cidadãos, entre outros. O objetivo geral deste trabalho foi verificar quais os procedimentos adotados para a indexação da informação jurídica e como isso poderia ser refletido em uma política de indexação. Como o conceito de informação jurídica é muito amplo, delimitou-se o espectro da pesquisa para jurisprudência, legislação e doutrina, investigando-se três instituições: Tribunal Regional Eleitoral de Pernambuco, Assembleia Legislativa de Pernambuco e Faculdade de Direito do Recife. A pesquisa foi caracterizada como exploratória, sendo realizada uma revisão de literatura acerca da organização do conhecimento e memória, políticas de indexação e informação jurídica. O instrumento de coleta de dados foi o questionário, além da observação nas instituições. A partir das observações in loco e análise das respostas ao questionário, foi possível elencar elementos que podem ser refletidos em uma política de indexação para informação jurídica.

Palavras-chave: Organização da informação. Políticas de indexação. Informação jurídica.

\begin{abstract}
Information Science is interdisciplinary, and established links with many areas, especially memory, because the emergence of the records of knowledge and the need for organization and access to information resulted in places of memory, which constituted practices for conservation, access and dissemination of information. Thus the organization and representation of knowledge, especially in contexts of information units, has a direct connection with the access, retrieval and ownership information. Moreover, while memory devices, allow the area or the discursive community can be understood and reconstructed, which applied to institutions that deal with the law may have wider effects in the sense of citizenship, promotion of access to information to citizens, among others. The aim of this study was to determine what procedures are adopted for indexing juridical information and how this could be reflected in a policy of indexing. However, as the concept of legal information is very broad, bounded to the spectrum of research on case law, legislation and doctrine. Was investigate three institutions: the Tribunal Regional Eleitoral, Assembleia Legislativa de Pernambuco and Faculdade de Direito do Recife. The research was characterized as exploratory, and performed a literature review of knowledge organization and memory, indexing policies and juridical information. The data collection instrument was a questionnaire, and observation in institutions. After observation and analysis of the responses to the questionnaire, it was possible to list elements that can be reflected in a policy of indexing for juridical information.
\end{abstract}

Keywords: Information organization. Indexing Policies. Juridical Information.

InCID: R. Ci. Inf. e Doc., Ribeirão Preto, v. 4, n. 1, p. 87-106, jan./jun. 2013. 


\section{Introdução}

Uma das características da Ciência da Informação (CI) é a interdisciplinaridade, isto porque, no seu processo dinâmico de desenvolvimento, constitui relações com outras áreas, como as ciências exatas, humanas e sociais. Disciplinas, como Documentação, Computação, Linguística, Comunicação etc., cooperam para a constituição da área quando seus conceitos e métodos são utilizados nas abordagens do objeto da CI: a informação (SARACEVIC, 1996).

Ainda no sentido da interdisciplinaridade, os profissionais que lidam com os registros e usos da informação também estabelecem uma ligação intensa com a memória, que, do mesmo modo como acontece com a informação, não é objeto exclusivo de uma área de estudo, sendo tratada sob perspectivas que se ajustam aos objetivos da área em questão (DODEBEI, 2002).

Devido às limitações naturais da memória individual, o homem passou a procurar meios de compensá-la com o uso de recursos externos, como exemplo, em As we may think, de Bush (1945), que sugere o uso de memórias artificiais para compensar a impossibilidade memorizar tudo. Assim, seriam fixados em um suporte físico símbolos que remetessem às ideias, transferindo o que está ligado à mente do indivíduo para um registro que pudesse ser compartilhado e acessado.

Gravar as ideias em algum suporte para acesso posterior, configurou-se na base para que a escrita fosse concebida, uma vez que "com o advento da escrita, os fatos poderiam ser registrados em suporte, não mais cabendo à memória humana a exclusiva função de reter e preservar informações" (MONTEIRO; CARELLI; PICKLER, 2008, p. 1). Com a evolução dos suportes, surgiu a necessidade de organização e acesso a esses registros, o que resultou na criação das chamadas instituições de memória, ou lugares de memória, que deveriam resguardar os registros do conhecimento nas suas diversas formas de materialização, que, de acordo com Homulos (1990), estão ligados ao paradigma da preservação e disseminação da memória e da informação.

Nesses lugares surgiu também a necessidade de sistematização e métodos para a organização, salvaguarda, além dos meios de como encontrar a informação partindo de um critério temático o que acabou aperfeiçoando o processo de recuperação da informação.

Nepomuceno (2011, p. 9) pontua o crescimento “[...] constante e geométrico do volume de informação, primeiramente verificado na área científica e, posteriormente, em toda a sociedade [...]" que trouxe consigo problemas de acesso e organização dos registros de informação gerados e acumulados pela sociedade, o que resulta numa demanda por 
instrumentos que facilitem a recuperação dessas informações, como a indexação, que se relaciona com a representação dos documentos e sua recuperação.

Desse modo, se não há critérios fixos para indexação de maneira sistematizada, por exemplo, a recuperação das informações não terá garantias quanto à sua eficácia, e essa é uma problemática recorrente quando não há uma política de indexação delineada e aplicada a diversos aspectos, desde a representação de um documento até a sua recuperação no âmbito da instituição mantenedora da unidade de informação.

É oportuno destacar que o tema deste trabalho refere-se aos procedimentos de indexação adotados pelos profissionais na perspectiva de SRI fechados, como bibliotecas e centros de informação tradicionais, e não em sistemas abertos, como repositórios colaborativos.

Assim, o propósito da pesquisa constitui-se em analisar os procedimentos adotados para realizar a atividade de indexação em uma área específica, neste caso, a jurídica, por considerá-la bastante avançada e com subsídios na biblioteconomia e em sua organização.

Partindo da problemática exposta, pode-se destacar a questão de pesquisa deste trabalho: quais os procedimentos adotados para realizar a atividade de indexação, face à inexistência de uma política especificamente no âmbito jurídico? Nesse sentido, para delimitar esse universo amplo que é o da informação jurídica, o foco de observação constituiu-se de três instituições que lidam com tipos específicos de documentos desse universo, a saber: Biblioteca da Faculdade de Direito do Recife (doutrina), Biblioteca da Assembleia Legislativa do Estado de Pernambuco (legislação) e Biblioteca do Tribunal Regional Eleitoral de Pernambuco (jurisprudência).

Visando a resposta para a questão proposta, a partir da pesquisa realizada, que é resultado da dissertação defendida no Programa de Pós-Graduação em Ciência da Informação de mestrado em Ciência da Informação ${ }^{1}$, o objetivo geral deste trabalho foi verificar quais os procedimentos adotados para a indexação da informação jurídica e como isso poderia ser refletido em uma política de indexação. De maneira específica, foi averiguada a existência de padronização da atividade de indexação, bem como de documentos que orientem essa atividade. Também foi observado como são realizadas a análise e a síntese documental e a forma como essas atividades são conduzidas pelos profissionais.

\footnotetext{
${ }^{1}$ BRAZ, M. I. Dispositivos de memória para informação jurídica: análise de procedimentos de indexação. 2013. Dissertação (Mestrado em Ciência da Informação) - Programa de Pós-Graduação em Ciência da Informação, Universidade Federal de Pernambuco, Recife, 2013.
} 
Partindo da hipótese de que SRIs funcionam com melhor precisão quando contam com vocabulários controlados, e que políticas de tratamento informacional contribuem para essa precisão, este estudo se justifica uma vez que a organização e a representação do conhecimento, em unidades de informação, guardam compromisso com a recuperação, o acesso e a apropriação da informação. Além disso, enquanto dispositivos de memória, permitem que a área ou a comunidade discursiva possam ser compreendidas e reconstituídas.

Essa constatação, quando aplicada às instituições que lidam com o exercício do Direito, pode ter efeitos mais abrangentes, graças à direta ligação com o exercício da cidadania, na intenção de promover, de modo mais eficaz, o acesso às informações as quais os cidadãos têm direito, melhorando o fluxo da informação nos sistemas que integram a instituição.

Nesse sentido, consideram-se dispositivos de memória os produtos oriundos da representação do conhecimento, porque, a partir de trabalhos terminológicos e terminográficos aplicados à documentação, torna-se possível que os espaços de memória, como, por exemplo, as unidades de informação, possam recuperar documentos e informação a respeito da área ou comunidade discursiva desejada.

\section{Organização do Conhecimento e Memória}

Para tratar de organização do conhecimento e sua relação com memória, é necessário estabelecer alguns conceitos e discuti-los, uma vez que abordar essas duas temáticas sem buscar um ponto em comum pode resultar em interpretações divergentes do objetivo deste trabalho, que se utiliza dos conceitos de Brascher e Café (2008). Para as autoras, é comum que se utilize os termos organização do conhecimento (OC) e organização da informação (OI) na mesma perspectiva, para designar os mesmos processos.

Porém, as autoras observam que enquanto a OI trata de “(...) um processo que envolve a descrição física e de conteúdo dos objetos informacionais" (BRASCHER; CAFÉ, 2008, p. 5), a OC resulta do “ [...] processo de modelagem do conhecimento que visa a construção de representações do conhecimento e [...] tem por base a análise do conceito e de suas características para o estabelecimento da posição que cada conceito ocupa num determinado domínio". Ou seja, a OI trata da representação da informação, enquanto a OC refere-se ao campo conceitual, e, de acordo com a natureza desta pesquisa, optou-se pelo uso de Organização do Conhecimento. 
O surgimento e a evolução da organização do conhecimento (OC) estão intimamente ligados com a questão da memória, isto porque as pesquisas que versam sobre OC têm relação direta com as aquelas dedicadas à história da escrita e do próprio livro, uma vez que o processo de leitura implica desde assimilar novas informações e percepções, até ao resgate de recordações e conhecimentos já alicerçados pela memória individual, influenciada pela memória social do grupo ao qual o indivíduo está vinculado. Assim, Pinho (2006, p. 6) assinala que "o círculo da produção e da recepção textual inicia o processo de reflexão no indivíduo que, com toda sua bagagem e inserção cultural, constrói o conhecimento".

É importante ponderar que o acesso aos registros do conhecimento, ou seja, aos documentos e evidências que possuam valor documental torna possível que o indivíduo possa desenvolver suas tarefas, logo, a organização dos registros documentais (OI) e a organização do conhecimento (OC) acabaram surgindo como um campo de estudos com o objetivo de resolver os problemas referentes à ordenação e acesso ao conhecimento.

A Organização do Conhecimento (OC) se estabelece como uma disciplina, inter e transdisciplinar que implica em análise, reflexão e aplicação de fundamentos científicos na verificação das técnicas de planejamento, tratamento e recuperação da informação.

Para que se possa compreender a natureza e a dinâmica da OC, é necessário abordar algumas nuances acerca do tema conhecimento. Para tanto, podemos considerá-lo como um processo de reflexão crítica e que pode levar um indivíduo a descobrir as características de um dado objeto ou fenômeno.

Dessa maneira, conhecimento é a tomada de consciência de um mundo vivido pelo homem, e, segundo Galliano (1986, p. 17) envolve duas situações: Sensibilidade física, que diz respeito a percepção física dos objetos físicos e Intelectual, que é a percepção de uma ideia, um princípio, uma impressão, nem sempre derivando de percepções físicas.

Para Habermas (1989), a base do conhecimento está na comunicabilidade e interação das percepções individuais e coletivas e na possibilidade de compartilhar, seja por registros, seja pela linguagem. Já o conhecimento social ou público, é contraído coletivamente por uma sociedade ou sistema social, o qual está livre e igualmente disponível para todos os membros daquela sociedade através de seus registros. Nesse sentido, para efeitos dessa pesquisa, considera-se como conhecimento social aquele registrado e divulgado (GUIMARÃES, 2000).

A necessidade de diferenciar os tipos de conhecimento está na questão da disponibilidade, uma vez que o conhecimento social está, a princípio, acessível através de consulta aos registros para aqueles que compõem a sociedade, sendo, portanto, esse tipo de conhecimento que se encontra armazenado em SRIs (KEMP, 1976). Por isso, Gomes (2009, 
p. 61) assinala que "no contexto da OC, conhecimento se refere a conhecimento científico e, mais especificamente, a conhecimento público, o qual é divulgado e disponibilizado ao público por meio de documentos", uma vez que a comunicabilidade é uma das principais características do conhecimento científico.

Dessa forma, o conhecimento social na perspectiva científica é fundamental para os arquivistas, bibliotecários, museólogos e cientistas da informação (MIRANDA, 2005), uma vez que constitui a base para as mais diversas atividades que são desenvolvidas no âmbito da Documentação, Biblioteconomia e Ciência da Informação.

\begin{abstract}
A ciência da informação é um campo dedicado às questões científicas e à prática profissional voltadas para os problemas de efetiva comunicação do conhecimento e de seus registros entre os seres humanos, no contexto social, institucional ou individual do uso e das necessidades de informação (SARACEVIC, 1996, p.47)
\end{abstract}

Sob esse aspecto, Barreto (2002) destaca que a CI passou do status de instituição de reflexão da informação para um campo onde algumas de suas nuances lidam com a ação mediadora ente informação e o conhecimento "acontecido" no indivíduo, ou como esse pode acessar o conhecimento registrado disponível em determinado sistema de informação.

A preocupação com o acesso à informação é recorrente, e remota ao princípio das primeiras bibliotecas, que tomaram para si a função de guarda do saber registrado. Mais tarde, com o aumento da aquisição e circulação das obras, acabou se tornando necessária a criação de instrumentos para que fosse possível classificar, identificar e hierarquizar o conhecimento disponível (PINHO, 2006).

A OC também se preocupa em descrever conteúdos, que abrangem a elaboração de resumos, classificação e indexação, porém, o enfoque sempre abrange os conceitos e não os objetos informacionais propriamente ditos, uma vez que “(...) não são os documentos, mas os conceitos contidos nos documentos que são classificados" (BRASCHER; CAFÉ, 2008, p. 6).

Nesse sentido, o estudo da OC nos permite o mapeamento conceitual de qualquer área do conhecimento, e, através da representação os documentos oriundos dos membros desses campos do saber, que se encontram nos lugares de memória - as unidades de informação.

Portanto, a perpetuação da memória, que foi garantida graças à sua socialização, não se deu de forma casual: foi preciso que há muito tempo evidências e documentos fossem preservados, e o mais importante, que se pudesse acessá-los; nesse sentido, os lugares de memória se configuram como verdadeiros guardiões da memória e da história, os quais Fernandes (1995) aponta como lugares onde se faz a gestão institucional dos saberes.

Os lugares de memória tradicionais, como museus, arquivos e bibliotecas, são definidos como instituições culturais, como ressalta Homulos (1990), que denomina essas de 
"instituições coletoras de cultura". O museólogo ainda ressalta que não devem existir papeis definidos nem fronteiras rígidas entre museus, arquivos e bibliotecas e indica que essas instituições sejam organizadas ao longo de um grande contínuo onde as bibliotecas e os museus se encontram cada um numa extremidade e os arquivos no meio do contínuo, porém, sem estabelecer um ciclo fechado, mas uma integração dos elementos, uma vez que suas atividades extrapolam a simples organização e guarda de documentos (FONTANELLI, 2005).

Como os lugares de memória abarcam o conhecimento e sua evolução, é necessário ter atenção ao modo como são abordados a recuperação, acesso e apropriação da informação com vistas à adoção de critérios para aumentar a precisão da indexação realizada, bem como alinhar a linguagem técnica dos documentos à linguagem dos usuários, considerando outros aspectos como as áreas do conhecimento que são contempladas pela instituição, etc. Esses critérios devem ser registrados, para que em situações, como por exemplo, mais de um indexador operando o sistema, não haja disparidade no modo como essa atividade é realizada.

\section{Políticas de Indexação}

A forma como se estabelece desde o desenvolvimento do acervo documental até a indexação nos espaços de memória se relaciona diretamente com os aspectos da instituição em si, sua missão, valores, cultura organizacional. Portanto, é necessário que a biblioteca desenvolva uma política de indexação, que se constitui de diretrizes que apontam escolhas técnico-administrativas (por isso política) considerando seu usuário e seu acervo.

Lancaster (2004, p. 6) considera a indexação como a "“...] descrição e caracterização de um documento através da representação do conteúdo temático [...]”, transcrevendo-os para linguagem documentária após sua análise. Dessa forma, é necessário estabelecer critérios com o objetivo de garantir a coincidência entre a linguagem utilizada na representação documentária e a linguagem de recuperação, utilizada pelos usuários.

Por outro lado, ao tratar de indexação dentro do contexto do ciclo documentário ${ }^{2}$ abordado por Rubi (2008) baseado em Shaw, podemos identificar esse processo como etapa intermediária, que dentro da acepção do tratamento documental, conforme Guimarães (2003), a indexação se compõe como elemento dialógico entre produtor e consumidor da informação.

\footnotetext{
2 De acordo com Shaw, citado por Rubi (2008), as etapas do ciclo documentário envolvem atividades de identificação, gravação, organização, armazenamento, recuperação e conversão em formas úteis, bem como a disseminação do conteúdo dos documentos. Por outro lado, cabe mencionar que a ideia de ciclo pode ser considerada controvertida, uma vez que denota possibilidades finitas, de recomeço, como um processo que retorna sempre ao estado inicial, sem evolução. Desse modo, a representação mais adequada para a o processo documentário seria a de uma espiral, a fim de não ter um início e um fim específico, permitindo que exista, no processo, intervenções e desenvolvimento das etapas que o compõe.
} 
Uma vez que o processo de indexação condiciona os resultados para uma estratégia de busca cujo resultado positivo ou negativo terá reflexo na recuperação da informação (FUJITA, 2003), pode-se apontar alguns aspectos comuns entre indexação e recuperação da informação a partir de Silva (2010) que adapta um modelo de Chaumier (1988, p. 76):

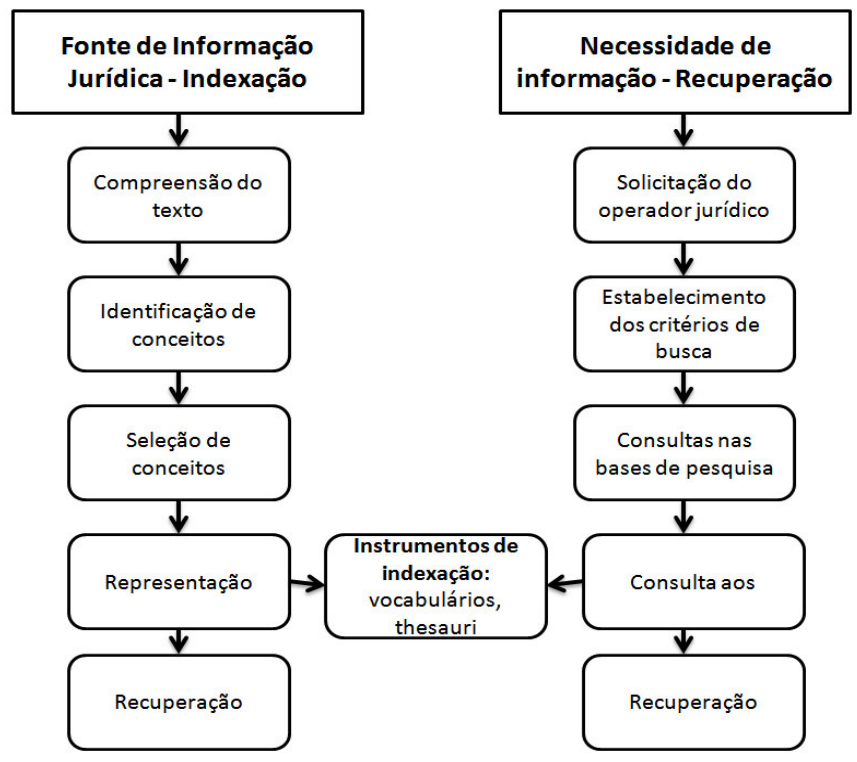

Figura 1 - Processo de indexação e recuperação da informação Fonte: Silva (2010, p. 26) adaptado de Chaumier (1988, p.76)

A escolha da linguagem documentária que será adotada, bem como a definição e caracterização das etapas que irão compor o processo de indexação é fundamental para que seja realizado com eficácia e precisão, se tornando, pois, orientações preestabelecidas para a tomada de decisões no âmbito do sistema.

Rubi (2004) aponta que a política de indexação é uma deliberação administrativa indispensável a SRIs, uma vez que seu estabelecimento define as características principais do sistema. Nessa perspectiva, Carneiro (1985, p. 221) afirma que

Uma política de indexação, como guia para tomada de decisões, deve levar em conta os seguintes fatores: a) características e objetivos da organização, determinantes do tipo de serviço a ser oferecido; b) identificação dos usuários, para atendimento de suas necessidades informacionais; c) recursos humanos, materiais e financeiros, que delimitam o funcionamento de um sistema de recuperação de informações.

O que Carneiro (1985) chama de política de indexação, Lancaster (1968 apud RUBI, 2004) denominou de "políticas de entrada de documento", e, a partir desses aspectos, o SRI poderá definir suas características principais, delimitando, por exemplo, se o foco maior será na revocação ou precisão, como proceder em relação à estratégia de busca, se esta será formulada pelo usuário e/ou através da escolha dos assuntos em uma lista pré-estabelecida e tempo de resposta. 
Para Carneiro (1985, p. 229), um SRI abrange uma série de decisões que se relacionam com cada uma das fases dos processos envolvidos, e que dessa forma, afetam o desempenho de um sistema como um todo. A autora cita os elementos que devem ser considerados quando da elaboração de uma política de indexação:

1. Cobertura dos assuntos: Quais são as áreas de interesse, onde estão situados os assuntos que serão tratados, e o nível de aprofundamento para a representação dos materiais;

2. Seleção e aquisição dos documentos-fonte: adequação ao nível intelectual e técnico dos usuários, ou seja, o domínio do conhecimento pelo público a que se destinam os materiais. Indicadores quanto à qualidade dos documentos como a autoria, confiabilidade dos dados, recursos financeiros empregados para adquiri-los são ponto importantes a considerar;

3. Processo de indexação :

3.1 Nível de exaustividade: os assuntos contidos no documento são reconhecidos na operação de indexação e convertidos na linguagem do sistema;

3.2 Nível de especificidade: precisão ao especificar o assunto de que trata o documento;

3.3 Escolha da linguagem: a linguagem utilizada para a indexação afeta o desempenho do SRI seja na estratégia de busca (como será representado o modo pelo qual usuário realizará a pesquisa), seja na indexação (institui a precisão para a representação do documento);

4. Estratégia de busca: definir se a busca será ou não delegada;

5. Tempo de resposta do sistema: tempo gasto entre o recebimento da solicitação e o fornecimento de uma resposta satisfatória; extraído.

6. Forma de saída: formato em que serão apresentados os resultados da busca, como resumos, referências, texto completo, etc.;

7. Avaliação do sistema: até que ponto o sistema satisfaz as necessidades dos usuários, quais falhas estão ocorrendo e de que forma podem ser corrigidas.

Dessa forma, uma política de indexação estabelecida constitui em um fator fundamental para garantir a qualidade como as informações são representadas e recuperadas, visto que a qualidade da indexação é um dos pontos principais para a satisfatória circulação/recuperação da informação. No caso da informação jurídica, isso pode facilitar tanto o exercício da cidadania, no sentido de promover de modo mais eficaz o acesso às informações as quais os cidadãos têm direito, e melhorar o fluxo da informação nos sistemas que integram as instituições jurídicas. 


\section{A Informação Jurídica}

Área interdisciplinar do conhecimento humano que procura regular a vida em sociedade, o direito está presente em diversos campos do conhecimento (PASSOS; BARROS, 2009). A palavra Direito advém do latim Directum, que denota muito reto ou muito justo (SILVA, 2010). No Brasil, o Direito sofreu influência dos institutos romanos, germânicos e canônicos, sendo dividido em dois grandes grupos:

- Direito Público: subdividido em interno e externo, rege as relações do Estado e do interesse público, serviços, bens públicos, licitação, tombamento de prédios históricos, etc.;

- Direito Privado: disciplina interesses individuais, isto é, da relação entre os particulares. A partilha de bens entre herdeiros ou cônjuges, compra e venda de bens móveis e imóveis são exemplos de atos regidos por essa espécie do Direito (GUSMÃO, 2006).

O Direito se manifesta e se estabelece por meio das normas jurídicas, cujas fontes são categorizadas em materiais e formais.

As fontes materiais se baseiam na origem e história do Direito, na sociologia, ética, política e costumes. Com base nessas fontes que o legislador determina as fontes formais. Gusmão (2006) aponta que as fontes materiais são as compostas por fenômenos sociais e dados extraídos da realidade social e tradições/costumes com as quais o legislador insere conteúdo ou matérias às fontes formais. "Com isso, podemos deduzir que as fontes formais são os meios pelos quais o Direito se apresenta: leis, regulamentos, decretos, jurisprudência, doutrina, tratados e outros" (SILVA, 2008, p. 100-101).

Nesse sentido, Passos (1994, p. 363) ainda conceitua informação jurídica (IJ) como toda a unidade de conhecimento humano que tem a finalidade de embasar
manifestações de pensamento de jurisconsultos, tratadistas, escritores jurídicos,
advogados, legisladores, desembargadores, juízes e todos aqueles que lidam com a
matéria jurídica, quando procuram estudar (do ponto de vista legal) ou regulamentar
situações, relações e comportamentos humanos, ou ainda quando interpretam e
aplicam dispositivos legais.

Percebe-se, pois, que há diferenças e peculiaridades entre as fontes de informação jurídica e que, para as finalidades documentárias de representação e recuperação da informação, exige-se, conforme ressalta Guimarães (1993), diferentes procedimentos de análise e representação temática, respeitando o conteúdo e a forma como se apresenta.

Desse modo, questões de acesso e recuperação são fundamentais na pauta de unidades de informação, e, no tocante à IJ, Passos e Barros (2009) assinalam que esta pode se 
manifestar por meio de três perspectivas: analítica (através da doutrina); normativa (pela legislação) e interpretativa (por meio da jurisprudência).

Acerca dessa classificação, podemos destacar:

Legislação - fonte de informação jurídica formal, atos ou dispositivos normativos emanados pelo poder estatal competente para disciplinar uma determinada situação no âmbito de uma área geográfica limitada. Pode também ser considerada como o conjunto de normas de um país, estado ou município ou ainda as leis acerca de uma determinada área jurídica.

Doutrina - Opinião de um especialista do direito, de caráter científico ou empírico, sobre qualquer matéria jurídica. É a teorização do conhecimento jurídico por meio de interpretações feitas por especialistas da área que definem e sistematizam os conceitos jurídicos, criando teorias e institutos jurídicos (PALAIA, 2006), e expostos em publicações como livros, artigos de periódicos, pareceres $^{3}$, trabalhos apresentados em congressos e demais meios que possibilitem sua publicação.

Jurisprudência - Considerada como fonte de informação, fornece elementos para sustentação e defesa das teses jurídicas. Acórdãos, decisões e sentenças, constituem a base para os profissionais do Direito verificarem como determinados problemas estão sendo julgados pelos magistrados e qual o melhor caminho a seguir (BARROS, 2004).

A variedade de especificidades que podem caracterizar a IJ faz que seja necessário selecionar, organizar, recuperar e disseminar essas informações adequadamente no âmbito das instituições, ou ainda para comunidades específicas e para a própria sociedade. Desse modo, essa tarefa é designada às unidades de IJ, que geralmente estão ligadas a órgãos públicos das três esferas (federal, estadual e municipal), que por sua vez estão conectadas a órgãos do Legislativo, Executivo, Judiciário e Ministério Público. Bibliotecas e arquivos judiciais são exemplos de fontes de IJ, além das bibliotecas de instituições de ensino superior que mantêm cursos de direito, além de escritórios de advocacia que também são consideradas unidades de IJ, ou seja, tem-se, então, "lugares de memória” especializados em informação jurídica, como por exemplo, as bibliotecas jurídicas, os arquivos dos tribunais, entre outros.

\footnotetext{
${ }^{3}$ Guimarães (1993) destaca que o parecer é um tipo especial de informação doutrinária, cuja principal característica é o maior grau de especificidade e maior objetividade na apresentação dos conceitos jurídicos, não se preocupando tanto com a estrutura científica da informação, mas com a resposta a uma questão contestável, colocada de modo objetivo. Porém, é necessário ressaltar que existem pareceres com funções diferentes daquelas que remetem à doutrina, pois, algumas não são se tratam de opiniões de jurisconsultos acerca de determinada questão jurídica.
}

InCID: R. Ci. Inf. e Doc., Ribeirão Preto, v. 4, n. 1, p. 87-106, jan./jun. 2013. 


\section{Método}

Para que o alcance dos objetivos de uma pesquisa seja efetivo, é necessário o planejamento coerente das etapas que garantam o seu cumprimento, desse modo, é necessário que se faça a escolha do método adequado.

Uma vez que se procura reunir e discutir aplicações e matérias referentes às políticas e procedimentos de indexação no sentido dos dispositivos de memória como produto dos trabalhos terminológicos e terminográficos, pode-se considerar a natureza da presente pesquisa como exploratória, que conforme Gil (2009, p. 27), “[...] tem como principal finalidade desenvolver, esclarecer [...] conceitos e ideias, tendo em vista a formulação de problemas mais precisos [...]".

Nesse sentido, ao passo que observamos as implicações desta pesquisa em um contexto específico (no caso as bibliotecas da Faculdade de Direito do Recife, da Assembleia Legislativa de Pernambuco e do Tribunal Regional Eleitoral de Pernambuco), verifica-se que ela se caracteriza como estudo de caso, que de acordo com Gil, (2009, p.58), é definido como "um estudo empírico que investiga um fenômeno atual dentro do seu contexto de realidade".

Destacamos que houve consentimento nas três instituições para realizar a pesquisa.

Para a reunião dos dados e informações pertinentes a este trabalho, foram utilizados os seguintes instrumentos: pesquisa bibliográfica, observação e questionário.

\section{Análise dos Dados}

Com relação ao questionário, as questões foram analisadas de maneira qualitativa através de análise de conteúdo, agrupando assuntos semelhantes. Nas questões dicotômicas fechadas, foi feito um paralelo com as respostas das outras questões e com as observações. Desse modo, a análise dos dados foi de cunho qualitativo no intuito de interpretar os procedimentos adotados para a atividade de indexação. Nesse sentido, a observação foi adotada e seu registro foi feito em um diário de campo, anotando o modus operandi dos indexadores. Dessa maneira, esses dados foram também analisados qualitativamente.

A seguir, pode-se observar o questionário aplicado aos chefes ou responsáveis pela indexação de cada biblioteca:

1. Que tipos de documentos são indexados?

2. Você recebeu algum tipo de capacitação para realizar a indexação?

3. Para realizar a indexação é adotado algum manual ou norma/resolução? Qual?

4. Detalhe a forma como você realiza a indexação. 
5. De quais partes do documento você extrai as palavras para indexação? Como você escolhe essas partes?

6. Na indexação você:

( ) Escolhe palavras específicas.

( ) Escolhe palavras gerais.

7. Na indexação, quanto ao número de palavras utilizadas, você:

( ) Escolhe poucas palavras.

( ) Escolhe muitas palavras.

8. Em geral, quantas palavras são estabelecidas para representar os documentos?

9. Você possui dificuldades para realizar a atividade de indexação? Quais?

10. Você utiliza algum tipo de controle terminológico para a indexação?

11. O que você entende sobre política de indexação?

Para sistematizar as respostas como uma maneira de facilitar a visualização e a análise, a partir desse momento a Biblioteca da Faculdade de Direito será identificada como A1, a Biblioteca da Assembleia Legislativa como A2 e a Biblioteca do Tribunal Regional Eleitoral como A3. Após a aplicação dos questionários aos chefes de cada biblioteca e da observação dos demais funcionários. A seguir destaca-se no Quadro 1 uma síntese das perguntas e respostas obtidas:

Quadro 1 - Síntese das Respostas

\begin{tabular}{|c|c|c|c|}
\hline Questão & $\begin{array}{c}\text { Instituição } \\
\text { A1 }\end{array}$ & $\begin{array}{c}\text { Instituição } \\
\mathrm{A2}\end{array}$ & $\begin{array}{c}\text { Instituição } \\
\text { A3 }\end{array}$ \\
\hline $\begin{array}{c}\text { 1. Tipos de } \\
\text { documentos que } \\
\text { indexa. }\end{array}$ & $\begin{array}{c}\text { Doutrina e um pouco } \\
\text { de legislação e } \\
\text { jurisprudência }\end{array}$ & Legislação estadual & $\begin{array}{c}\text { Doutrina e } \\
\text { jurisprudência do } \\
\text { Tribunal }\end{array}$ \\
\hline $\begin{array}{l}\text { 2. Recebeu } \\
\text { capacitação para } \\
\text { indexação? }\end{array}$ & Sim. & Sim. & Sim. \\
\hline $\begin{array}{l}\text { 3. É adotada alguma } \\
\text { norma/manual de } \\
\text { procedimentos? }\end{array}$ & $\begin{array}{l}\text { Sim, uma "norma" } \\
\text { interna. }\end{array}$ & $\begin{array}{c}\text { Manual de indexação } \\
\text { e política de } \\
\text { indexação da ALMG }\end{array}$ & $\begin{array}{c}\text { Manual de indexação } \\
\text { de jurisprudência da } \\
\text { JF, e Res.155/2012 do } \\
\text { TRE-PE }\end{array}$ \\
\hline $\begin{array}{l}\text { 4. De quais partes do } \\
\text { documento são } \\
\text { retirados os } \\
\text { descritores? }\end{array}$ & $\begin{array}{c}\text { Geralmente dos } \\
\text { elementos pré-textuais } \\
\text { como sumário, } \\
\text { introdução etc. }\end{array}$ & $\begin{array}{l}\text { Do corpo da norma, } \\
\text { artigo por artigo }\end{array}$ & $\begin{array}{c}\text { Folha de rosto, } \\
\text { sumário e introdução } \\
\text { dos livros; acórdãos. }\end{array}$ \\
\hline 5. Descritores de & Específico. & Específico. & Específico. \\
\hline
\end{tabular}




\begin{tabular}{|c|c|c|c|}
\hline $\begin{array}{c}\text { cunho geral ou } \\
\text { específico? }\end{array}$ & Muitos. & Poucos. & Poucos. \\
\hline $\begin{array}{c}\text { 6. Muitos ou poucos } \\
\text { descritores? }\end{array}$ & Cerca de 4. & $\begin{array}{c}\text { Depende do tamanho } \\
\text { da norma. }\end{array}$ & De 3 a 5. \\
\hline $\begin{array}{c}\text { 7. Em geral, quantos? } \\
\begin{array}{c}\text { 8. Possui alguma } \\
\text { dificuldade em } \\
\text { indexar? }\end{array}\end{array}$ & $\begin{array}{c}\text { Sim. Em matérias } \\
\text { muito específicas. }\end{array}$ & $\begin{array}{c}\text { Sim, depende do } \\
\text { conteúdo da norma. }\end{array}$ & Não. \\
\hline $\begin{array}{c}\text { 9. É usado algum tipo } \\
\text { de controle } \\
\text { terminológico? }\end{array}$ & Sim. & Sim. & Sim. \\
\hline
\end{tabular}

Fonte: Dados da Pesquisa

A análise do quadro demonstra, em grande parte, os aspectos que devem estar presentes em uma política de indexação de informação jurídica, como os tipos de documentos que integram o acervo, manual de procedimentos, as macroestruturas que devem ser observadas para a identificação dos conceitos, o grau de especificidade e exaustividade, o tipo de controle terminológico, etc.

A partir das respostas e das observações foi possível concluir que, mesmo de forma inconsciente, os sujeitos realizam a indexação privilegiando determinadas características de cada tipo documental. Como por exemplo, para doutrina, elementos textuais comuns às publicações como introdução, sumário, catalogação na fonte; os acórdãos, no caso da jurisprudência, e os artigos que constituem as normas, para a legislação.

Entretanto, considerando que a análise documentária compreende análise, síntese e representação, a segunda etapa não é observada em nenhum dos contextos, o que acaba refletindo na compreensão leitora por parte do bibliotecário. Outro ponto é a falta de formalização dos elementos que devem estar presentes quando se tratar de indexação de informação jurídica, como a indicação de quais macroestruturas considerar, ponderando as especificidades de cada tipo documental que esteja inserido na classificação de doutrina, legislação ou jurisprudência.

Após a observação e aplicação do questionário nas bibliotecas que integraram o universo de pesquisa, foi possível chegar a algumas conclusões acerca destas, e que podem refletir também a realidade de outras instituições:

- Não é adotado manual de procedimentos contextualizado - Geralmente as bibliotecas utilizam manuais de operação do sistema de gerenciamento eletrônico do acervo, ou 
adotam manuais de outras instituições, que privilegiam realidades diferentes, que muitas vezes não abordam a mesma matéria;

- Há uma conduta semelhante por parte dos bibliotecários de realizar indexação do mesmo tipo de documento no que concerne à análise, embora não tenha sido observada a etapa da síntese - apenas uma das bibliotecas tende a focar em macroestruturas determinadas, como é o caso da jurisprudência, onde o enfoque é o acórdão, ou ainda, no caso da doutrina, elementos como título, sumário e introdução, que se repetem na maioria das obras doutrinárias. Contudo, a falta de padrão na observação das macroestruturas se reflete na compreensão leitora do bibliotecário, que aliada à ausência da etapa de síntese pode prejudicar a compreensão de conteúdos;

- Predominância da especificidade - Foi observado que a preferência pela especificidade tem duas causas: a natureza especializada das bibliotecas e dos conteúdos dos documentos, que refletem tanto os anseios da instituição a qual estão vinculadas e ainda o tipo de púbico usuário das informações. Desse modo, há necessidade de um tratamento informacional privilegiando a linguagem especializada;

- Falta de atenção ao controle da qualidade dos instrumentos de controle terminológico utilizados - em um dos casos não foi verificada a existência de um controle de qualidade no vocabulário controlado, sendo este alimentado a partir das demandas por novos descritores. Embora exista certo controle para as entradas, constatou-se, nas observações, que são necessárias avaliações/atualizações nesse vocabulário de forma sistemática;

- O entendimento dos bibliotecários entrevistados com relação às políticas de indexação ainda é incipiente - esse fato pode ser constatado principalmente pelo fato de não haver uma política de indexação formalizada em nenhuma das bibliotecas visitadas. Como também não estão formalizados pontos necessários para a manutenção das rotinas e serviços desenvolvidos, é natural que seja um tema pouco explorado e compreendido por esses bibliotecários.

Considerar os pontos adequados ao estabelecer uma política de indexação é fator fundamental para garantir a qualidade como as informações são representadas e consequentemente recuperadas, visto que a qualidade da indexação é um dos pontos principais para a satisfatória circulação/recuperação da informação.

Logo, se não há uma política que atenda às demandas e reflita os objetivos e a filosofia da instituição, é possível que surjam, ao longo do tempo, disparidades entre o ponto de vista 
dos bibliotecários, o modo como executam suas tarefas, em especial a indexação, pelo fato de ser um processo subjetivo, além da forma como são desenvolvidos, avaliados e utilizados instrumentos como linguagens para o controle do vocabulário, manuais de indexação.

Todos esses aspectos serão refletidos na qualidade do sistema, e, portanto, nas condições como o serviço é prestado aos usuários. Portanto, é possível afirmar que o trabalho documentário é como uma cadeia, onde serão refletidos os pontos considerados e trabalhados pelas decisões que devem estar previstas numa política de indexação constituída para a instituição.

\section{Considerações Finais}

Representar o conteúdo dos documentos buscando um denominador entre as perspectivas da instituição, a linguagem de indexação e aquela utilizada pelos usuários é um desafio para qualquer contexto que lide com a guarda e disseminação de informações.

Nesse sentido, os lugares de memória detêm o importante papel de guardiões e propagadores da memória, no que se refere às representações do conhecimento registradas. Logo, é necessária atenção à forma como são abordados a recuperação e acesso à informação, que se fundamentam nas atividades de representação do conhecimento e da informação através dos processos de cunho terminológico e terminográfico, em especial a indexação. Assim, durante o desenvolvimento da pesquisa foi demonstrado que a política de indexação consiste em uma filosofia que reflete os objetivos e interesses da instituição, norteando procedimentos de indexação, considerando variáveis que podem influenciar esse processo.

A partir das observações nas bibliotecas, é possível citar os elementos que podem ser refletidos em uma política de indexação para informação jurídica:

- Necessidade de adotar um manual de indexação contextualizado - o manual deve ser constituído de acordo com o contexto da biblioteca, e pode ser estabelecido no mesmo documento que trata da política de indexação.

- Apontar quais as macroestruturas que devem ser observadas para a etapa da análise diante das observações, é possível destacar as macroestruturas que devem ser observadas de acordo com cada tipo documental: para doutrina, observou-se que há a tendência em considerar elementos pré-textuais, presentes na maioria das obras doutrinárias, como título e subtítulo, resumo (se houver), sumário, introdução, palavras ou em destaque, além da conclusão; para legislação, constatou-se que é feita a leitura do documento no todo, devido à opção da biblioteca, mas poderia privilegiar 
a parte preliminar das normas (epígrafe, ementa e preâmbulo) como regra geral; para jurisprudência, foi constatado que a leitura do acórdão, na maioria das vezes, é suficiente para chegar-se ao assunto central do documento e aos possíveis descritores;

- Cumprir todas as etapas da análise documentária - como foi observado que a etapa da síntese não é cumprida, refletindo na compreensão leitora, na política de indexação deve-se destacar as fases da análise documentária e a importância de cumpri-las;

- Preferência pela especificidade - foi observada a predominância da linguagem especializada e um alto grau de aprofundamento temático. Para a IJ, é preferível que essa seja a regra, uma vez que se trata da natureza especializada tanto das bibliotecas, dos conteúdos dos documentos, bem como usuários que buscam matérias específicas;

- Exaustividade - embora se opte pela especificidade, não é privilegiada a exaustividade, ou seja, não há amplo aprofundamento na análise e representação na maioria das situações. Por outro lado, a escolha pela exaustividade deve considerar o tipo de documento e seu conteúdo, como por exemplo, quando for indexada uma lei ordinária que trata de diversos assuntos é necessário que todos os conteúdos sejam representados, e, portanto, o grau de exaustividade será maior do que na indexação de um artigo de periódico que verse sobre um assunto específico;

- Número de descritores - as respostas do questionário apontam para um número variável de termos. Porém, as observações assinalam que o número médio de descritores para doutrina e jurisprudência de modo geral é de 5 descritores. Por outro lado, ao considerar que existem normas extensas que abordam diversas matérias e aspectos, estas devem conter um número maior de termos (cerca de 15);

- Adoção de um controle terminológico - uma vez que se opta pela especificidade, é necessário adotar um instrumento de controle do vocabulário, com o intuito de normalizar os descritores, especialmente quando se trata de uma área do conhecimento específica com tipos documentais característicos. Em todas as instituições observadas foi adotado um instrumento para controle do vocabulário. Assim, deve-se privilegiar a contextualização e o modo como serão atualizados e avaliados esses instrumentos.

Essas considerações aplicadas ao contexto da IJ ensejam algumas ressalvas, visto que geralmente os órgãos que lidam com esse tipo de informação emanam, eles mesmos, parte do material que compõe seu acervo documental. Por exemplo, as faculdades de direito, mesmo que abarquem legislação e jurisprudência, dando suporte às atividades didáticas, exercem maior enfoque à doutrina, uma vez que também produzem esse tipo de IJ, como as 
monografias de conclusão de curso, os artigos científicos publicados por seus professores e alunos, etc. Nesse sentido, o mesmo ocorre com os tribunais, que produzem jurisprudência e com as assembleias legislativas, que emanam leis e onde esses tipos documentais consequentemente integrarão seus acervos.

Considerando o âmbito jurídico, a qualidade dos serviços desenvolvidos no que tange a representação das informações e sua recuperação tem uma dimensão singular: promover o exercício da cidadania, otimizando o acesso às informações as quais os cidadãos têm direito e melhorando o fluxo da informação nos sistemas que integram as instituições jurídicas, muitas vezes afetadas por dificuldades na recuperação da informação devido à inadequada indexação.

Portanto, constituir uma política de indexação adequada deve ser uma prioridade para qualquer instituição que ofereça serviços de informação, como os órgãos que produzem ou lidam com a informação jurídica, considerando também que essas políticas não devem ser inertes, havendo sempre atenção no sentido de serem periodicamente avaliadas e atualizadas.

\section{Referências}

BARReto, A. A. A condição da informação. São Paulo em Perspectiva, São Paulo, v. 16, n. 3, 2002. Disponível em: <http://www.scielo.br/scielo.php?script=sci_arttext\&pid=S0102-

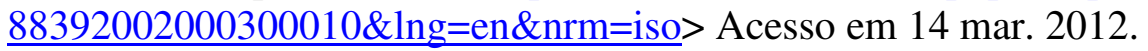

BARROS, L. V. Fontes de informação jurídica. In: PASSOS, E. (Org.). Informação jurídica: teoria e prática. Brasília: Thesaurus, 2004, p. 201-225.

BRÄSCHER, M.; CAFÉ, L. Organização da informação ou organização do conhecimento? In: ENCONTRO NACIONAL DE PESQUISA EM CIÊNCIA DA INFORMAÇÃO, 9, 2008, São Paulo, Anais. São Paulo: ANCIB, 2008. Disponível em: <http://www.ancib.org.br/media/dissertacao/1835.pdf>. Acesso em: 30 out. 2011.

BUSH, V. As we may think. The Atlantic Monthly, julho, 1945. Disponível em: http://www.theatlantic.com/magazine/archive/1945/07/as-we-may-think/303881/ Acesso em 16 out. 2012.

CARNEIRO, M. V. Diretrizes para uma política de indexação. Revista da Escola de Biblioteconomia da UFMG, Belo Horizonte, v. 14, n. 2, p. 221-241, set. 1985.

CHAUMIER, J. Indexação conceitos etapas. Revista Brasileira de Biblioteconomia e Documentação, v. 21, n. 1/2, p. 63- 79, jan./jun. 1988.

DODEBEI, V. L. D. Tesauro: linguagem de representação da memória documentária. Niterói: Intertexto; Rio de Janeiro: Interciência, 2002. 
FERNANDES, G. C. o objeto de estudo da Ciência da Informação. Informare - Cadernos do Programa de Pós-Graduação em Ciência da Informação, Rio de Janeiro, v. 1. n. 1, p. 25-30, jan./jun. 1995.

FONTANELLI, S. A. Centro de memória e ciência da informação: uma interação necessária. São Paulo, 2005. 105f. Trabalho de Conclusão de Curso (Bacharelado) Departamento de Biblioteconomia e Documentação. Escola de Comunicações e Artes. Universidade de São Paulo, São Paulo, 2005.

FUJITA, M. A leitura documentária do indexador: aspectos cognitivos e linguísticos influentes na formação do leitor profissional. 2003. 321f. Tese (Livre-Docência em Análise Documentária e Linguagens Documentárias Alfabéticas) - Faculdade de Filosofia e Ciências, Universidade Estadual Paulista, Marília, 2003.

GALliANO, A. G. O método científico: teoria e prática. São Paulo: Harbra, c1986.

GIL, A. C. Métodos e técnicas de pesquisa social. 6. ed. São Paulo: Atlas, 2009.

GOMES, H. E. Tendências da pesquisa em organização do conhecimento. Pesq. bras. Ci. Inf., Brasília, v.2, n.1, p.60-88, jan./dez. 2009.

GUIMARÃES, J. A. C. Formas da informação jurídica: uma contribuição para sua abordagem temática. Revista Brasileira de Biblioteconomia e Documentação, São Paulo, v. 26, n. 1/2, p. 41-54, jan./jun. 1993.

Politicas de análisis y representación para la gestión del conocimento en las organizaciones. Scire, Zaragoza, v. 6, n. 2, p. 48-58, jul/dic. 2000.

A análise documentária no âmbito do tratamento da informação: elementos históricos e conceituais. In: RODRIGUES, G. M.; LOPES, I. L. (Org.). Organização e representação do conhecimento: na perspectiva da Ciência da informação. Brasília: Thesaurus, 2003. p. 100-117.

GUSMÃO, P. D. Introdução ao estudo do direito. 37. ed. Rio de Janeiro: Forense, 2006.

HABERMAS, J. Consciência moral e agir comunicativo. Rio de Janeiro: Tempo Brasileiro, 1989.

HOMULOS, P. Museums to libraries: a family of collecting institutions. Art libraries Journal, v. 15, n. 1, p. 13-11, 1990.

KEMP, D. A. The nature of knowledge: an introduction for librarians. London: C. Bingley, 1976.

LANCASTER F. W. Indexação e resumos: teoria e prática. 2. ed. Brasília: Briquet de Lemos, 2004.

MIRANDA, M. L. C. Organização e representação do conhecimento: fundamentos teórico- metodológicos na busca e recuperação da informação em ambientes virtuais. 2005. 
354 f. Tese (Doutorado em Ciência da Informação) - Universidade Federal do Rio de Janeiro, Rio de Janeiro, 2005.

MONTEIRO, S. D.; CARELLI, A. E.; PICKLER, M. E. V. A Ciência da Informação, Memória e Esquecimento. DataGramaZero, v.9, n.6, dez. 2008. Disponível em http://www.datagramazero.org.br/dez08/Art_02.htm Acesso em 16 out. 2012.

NEPOMUCENO, C. Macrocrise da informação digital: muito além das explosões informacionais. 2011149 f. Tese (Doutorado em Ciência da Informação) - Universidade Federal Fluminense/IBICT, Rio de Janeiro, 2011.

PALAIA, N. Noções essenciais de direito. 3. ed. São Paulo: Saraiva, 2006.

PASSOS, E. O controle da informação jurídica no Brasil: a contribuição do Senado Federal. Ciência da Informação, Brasília, v. 23, n. 3, p. 363-368, set./dez. 1994.

PASSOS, E.; BARROS, L. V. Fontes de informação para a pesquisa em direito. Brasília: Briquet de Lemos, 2009.

PINHO, F. A. Aspectos éticos em representação do conhecimento: em busca do diálogo entre Antonio García Gutiérrez, Michèle Hudon e Clare Beghtol. 2006. 123 f. Dissertação (Mestrado em Ciência da Informação) - Faculdade de Filosofia e Ciências, Universidade Estadual Paulista, Marília, 2006.

RUBI, M. P. A política de indexação na perspectiva do conhecimento organizacional. 2004. 135 f. Dissertação (Mestrado em Ciência da Informação) Faculdade de Filosofia e Ciências, Universidade Estadual Paulista; CAPES, Marília, 2004.

Política de indexação para construção de catálogos coletivos em bibliotecas universitárias. 2008. 166 f. Tese (Doutorado em Ciência da Informação) - Faculdade de Filosofia e Ciências, Universidade Estadual Paulista, Marília, 2008.

SARACEVIC, T. Ciência da informação: origem, evolução e relações. Perspectivas em Ciência da Informação, Belo Horizonte, v. 1, n. 1, p. 41-62, jan./jun. 1996.

SILVA, A. G. Leitura documentária das fontes de informação jurídica. 2008. $221 \mathrm{f}$. Dissertação (Mestrado) - Escola de Comunicações e Artes, Universidade de São Paulo, São Paulo, 2008.

Fontes de informação jurídica: conceitos e técnicas de leitura para o profissional da informação. Rio de Janeiro: Interciência, 2010. 